\title{
Am I a Backpacker? \\ Factors Indicating the Social Identity of Chinese Backpackers
}

\begin{abstract}
The question of what constitutes backpacker identity has been one of the central topics of backpacking tourism research. With the economic boom in China, the last two decades witnessed the proliferation of Chinese backpackers. By adopting quantitative methods, this study provides a comprehensive understanding of what makes one a "backpacker" in China. Comparing results from t-tests, binomial logistic regression, and multiple linear regression, it is found that Chinese backpackers' social identities are mostly associated with external-oriented motivation, work alienation, and detachment from home centers. Behavioral characteristics, which have up until now been widely used to define backpackers, have very limited relationship to their identities in China. This finding calls for future research to rethink what is a backpacker. The research makes an important contribution to the understanding of this growing market and its particular identity factors.
\end{abstract}

\section{Keywords}

Backpacker, backpacking tourism, social identity, travel behavior, motivations, sense of alienation 


\section{Introduction}

"Identity", which is essentially about the question of "Who am I?", is a core concept in social sciences, and has gained increasing attention in the field of tourism research, and most notably in backpacker tourism research (S. A. Cohen 2010; Desforges 2000; O'Regan 2016). Backpacking tourism, especially when it takes place in what are considered exotic "Third World" destinations, is constructed as an ideal way to develop and represent one's virtues such as adaptability, worldliness, and willpower (Desforges 1998; Munt 1994). In addition, the label "backpacking" is frequently bestowed with ideals of freedom, personal development and fulfillment (O'Reilly 2005). Therefore, the term "backpacker" is far more than a category of tourists, but is also a social identity with its unique group culture and values. However, from "drifters" (E. Cohen 1973) in the 1970s through to contemporary backpackers, the characteristics and boundaries of this group are said to be constantly evolving (Ateljevic and Doorne 2004). This raises a fundamental, and constantly shifting, question: What makes a traveler a backpacker?

Previous studies address this question in different ways (E. Cohen 1973; Larsen, Øgaard, and Brun 2011; Loker-Murphy and Pearce 1995; Sørensen 2003; Uriely, Yonay, and Simchai 2002; Vogt 1976). However, the majority of studies have taken backpackers to be usually middle-class and young people, from affluent Western societies, including USA, Europe, Australia, Canada, and New Zealand (Adler 1985; S. A. Cohen 2011; Tomazos 2016). Non-Western countries only feature in that they comprise the "landscapes" for the backpacking activities (E. Cohen 2006; Howard 2007; Wilson and Richards 2008). Increasingly, however, scholars are reaching a consensus that backpackers should not be regarded as a homogeneous group, and that, rather, their characteristics and identity construction may vary according to their national and cultural 
background (Enoch and Grossman 2010; Maoz 2007). In addition, greater understanding of the emergent backpackers from non-Western countries is called for.

In Mainland China, rapid growth in domestic "backpacker" tourism has occurred since the late 1990s (Zhu 2009). Several backpacking-oriented websites, like qyer.com, mafengwo.cn, and doyouhike.net, are now popular. The Youth Hostel Association China (YHA China) opened 315 hostels by the end of 2016 (YHA China 2016), and other independent backpacking hostels have proliferated in recent years as well. Several books, movies and TV programs relating to backpacking tourism have emerged including, To Berlin by Thumb, Backpacking during Ten Years, and A Belated Gap Year. This development is accompanied by a growing research interest in this group, especially regarding their behavioral characteristics and motivations (Chen and Weiler 2014; Luo, Huang, and Brown 2015; Ong and du Cros 2012). However, it is interesting that with the apparent increasing popularity of backpacking in China, more travelers who travel backpack-like do not wish to be called backpackers, requiring novel marketing and management strategies for this niche market. However, little research has been conducted to understand questions of identity of Chinese backpackers. To address this gap, this research explores what is considered to make one a "backpacker" in the Chinese context. Adopting quantitative methods, the factors related to the social identity of Chinese backpackers are identified. This work aims not only to make a contribution to identity studies on backpackers more broadly, but also to add to the knowledge on non-Western backpackers, and specifically Chinese backpackers. 


\section{Literature Review}

\section{"Backpacker": a definition or an identity?}

The study of contemporary backpackers can be traced back to the 1970s. Erik Cohen's seminal works during that early period (E. Cohen $1972 ; 1973 ; 1979)$ are broadly considered to be the theoretical foundation of this field. He developed a typology of tourist roles based on a continuum of possible combinations of familiarity and novelty (E. Cohen 1972): the organized mass tourist, the individual mass tourist, the explorer, and the drifter. The first two, who are considered "institutionalized" tourists, are dominated by familiarity and heavily rely on services offered by tourism establishments. The last two, who are referred to as "non-institutionalized" tourists, are dominated by novelty and are loosely attached to tourism establishments. Among these four types, the drifter is seen as the model, or prototype, for the backpacker (E. Cohen 2003), and is described as the "traveler" (rather than tourist per se) with a flexible itinerary and low budget, and who seeks authenticity and adventure, and is willing to be immersed in "other" cultures.

Since Cohen's earlier work, an increasing amount of research about backpackers has featured in the tourism studies literature. However, even with this literature expansion, it is becoming more difficult to identify the boundaries of the group. Besides drifters, various other terms are used to define these non-institutionalized tourists, such as youth tourists (Ten Have 1974), wanderers (Vogt 1976), hitchhikers (Mukerji 1978), long-term budget travelers (Riley 1988), and backpackers (Pearce 1990). Although they share some common characteristics, these different terms convey different connotations. For example, Cohen's (1973) drifter and Ten Have's (1974) youth tourists are found to be associated with counter-culture, and have a strong stance in 
relation to certain social-political issues. Riley's (1988) anthropological research from the 1980s challenges this idea, however, with Riley arguing that these tourists have evolved into a group with somewhat diminished counter-cultural image. Indeed, Riley (1988) contends that backpackers have become more inward-oriented, and increasingly focus on their own mental and spiritual growth. Furthermore, Pearce's (1990) use of the term "backpacker" went so far as to imply the institutionalization of these supposedly non-institutionalized tourists.

It can therefore reasonably be inferred that this group has experienced an ongoing evolution since it first emerged. This may be due to the changes in social-historical contexts the backpackers generate from (Ateljevic and Doorne 2004; O’Reilly 2006). In addition, it has become apparent that backpackers from different nationalities and cultures invariably have different characteristics (Enoch and Grossman 2010). For instance, compared to Western backpackers, Israeli backpackers show a highly collective orientation, a tendency to dismiss local residents and other nationalities, and a preference for traveling in groups (Maoz 2007). This presents a challenge in understanding what makes a backpacker a backpacker. Two streams of research have hence developed to answer this question: the first stream focuses on "Who they are"; the second one concerns "Who am I?".

Scholars following the first stream look for objective criteria in order to make a clear definition for this group (Loker-Murphy and Pearce 1995; Uriely, Yonay, and Simchai 2002). Uriely et al.'s work (2002) makes an illuminating contribution to this question. They introduce two analytical constructs - "form" and "type" - to clarify the definition. The former refers to visible institutional arrangements and travel practices, such as length of trip, flexibility of the itinerary, visited destinations, and attractions. The latter refers to more intangible psychological attributes, including travelers' motivations, their attachments to home societies, and the 
meanings they assign to their trips. Uriely et al. argue that the previous definitions, including drifters and wanderers, used form- and type-related attributes indistinguishably, whereas, because modern backpackers are heterogeneous in type-related attributes, the definition of "backpacker" should be based on form only.

The second stream of the backpacker identity research moves away from attempts to define backpackers from an outsider's perspective, focusing instead on exploring how backpackers view themselves (O’Reilly 2005; O'Regan 2016; Sørensen 2003). Sørensen (2003) argues that form-related attributes can only serve as guidelines to understand backpackers, and cannot be the objective criteria to distinguish backpackers from other tourists, because there are many travelers who do not meet the criteria but still label themselves as backpackers. As Tajfel (1982) puts it, identification with a social group is not only cognitive but also emotional. People label themselves as backpackers because not only do they meet some objective criteria, but also they accept the meanings and values bestowed on this social identity and have a sense of belongingness.

Social identity as a backpacker

Following the second stream, the label "backpacker", which provides meaning for some independent travelers, thereby can be understood as a component of self or a social identity for these individuals. According to social identity theory, which was originally formulated by Tajfel and Turner (Tajfel 1982; Tajfel and Turner 1979), social identities are constructed through the process of self-categorization through which people label themselves as a member of a particular social group or category.

In the context of tourism, there are various labels by which independent travelers may choose to identify themselves, with the most widely mentioned being "tourist", "traveler" and 
"backpacker" (O'Reilly 2005). Each is endowed with different meanings among backpacker communities. "Tourist" is a label that most backpackers are not willing to have attached to them as "tourist" in their eyes has negative connotations. Tourists are seen as relying on tourism agencies and facilities, staying in the "environmental bubble" produced by the tourism industry, seeking comfort and enjoying "pseudo-events" (Boorstin 1964). Additionally, they are perceived as showing little respect to local society and having more negative impacts on destinations (Howard 2007). In contrast, "backpackers" and "travelers" are more positively valued. They possess certain traits that are diametrically opposed to those of "tourists", such as independence, courage, and environmental friendliness. Interestingly, however, many of these independent travelers prefer to use the term "traveler" instead of "backpacker" to describe themselves (Richards and Wilson 2004). O'Reilly (2005) believes that this is caused by the loss of "street cred" of the term "backpacker", due to its "massification" and institutionalization in recent years.

This label selection by backpackers also suggests another important function of social identity. It not only focuses the group members but also separates them from others. Boundaries of social groups, therefore, are developed as a mechanism of differentiation. Group boundaries can be determined by natural factors (like gender and ethnicity), but in more cases, they are symbolic and socially constructed (Lamont and Fournier 1992), which makes them blurred, unstable, and constantly changing. As social identity mediates the relationship between social structure and individual agency (Hogg, Terry, and White 1995), with a change of social structure, individual behavior adjusts to the new context. Consequently, the connotation of the specific social identity and symbolic boundaries of a social group is reproduced and reconstructed. 
It is therefore necessary to recognize the changing boundaries of "backpacker" in different social contexts. Based on the literature, it can be inferred that, both physical and psychological factors, or in Uriely et al.'s terminology, both form- and type-related attributes, are likely to be considered as symbolic boundaries by backpackers themselves. The following materials then illustrate the most discussed factors in the previous research.

\section{Travel behavior}

Travel behavior, which can be regarded as form-related attributes, is the most significant visible symbolic boundary of backpackers. Riley's (1988) “long-term budget travelers" emphasizes two basic characteristics of backpackers' travel behavior: trip length and budget. Another widely accepted definition, that made by Loker-Murphy and Pearce (1995), is also based on travel behavior. They name five key characteristics of backpackers: "a preference for budget accommodation; an emphasis on meeting other people; an independently organized and flexible travel schedule; longer rather than brief holidays; and an emphasis on informal and participatory recreation activities" (Loker-Murphy and Pearce 1995, 830-831). Additional behavioral traits highlighted by scholars include a preference for getting off the beaten track when selecting destinations (Welk 2004) and high-risk adventures (Elsrud 2001; Larsen, Øgaard, and Brun 2011).

However, these form-related criteria are challenged by the evolution of backpackers with the vicissitude of time. For example, Sørensen (2003) cites a strong growth in short-term backpacking, which is similar to ordinary backpacking in other respects, but is limited by length of trip. Besides the "short-term backpacker", some scholars identify another new sub-group of backpackers - flashpackers (Hannam and Diekmann 2010; Paris 2012). Travel expenditure and technology use are the two key traits differentiating this group from traditional backpackers. 
They still travel backpacker-like, but they are more affluent and have higher travel budgets. They also rely on technological devices such as cell phones, iPads, and laptops while traveling. In addition, the criteria of trip length and budget are even less applicable to Chinese backpackers. It is known that Chinese backpackers have much shorter average lengths of trips than their Western counterparts, and they are also known to spend more money during their journeys (Chen, Bao, and Huang 2014b; Zhu 2009). Therefore, it is debatable today that backpackers accept travel behavior as an important factor in their identity construction.

\section{Motivation}

Among type-related attributes, backpackers' motivations are most studied by scholars. When Cohen (1973) drew his attention to drifters, he noticed the heterogeneity of backpackers in motivations, and classified them into the "outward oriented", concerned with experiencing the host culture, and the "inward oriented", concerned with the youth culture to which they belonged. Loker-Murphy (1997) is the first scholar to classify backpackers based on their motivations in a quantitative way. She completed a marketing-oriented survey to examine backpackers' motivations with respect to Pearce's travel career ladder, and found four segments: escapers/relaxers, social/excitement-seekers, self-developers, and achievers. Since then, scholars have made further efforts to understand backpackers' motivations (Hindle, Martin, and Nash 2015; Pearce and Foster 2007; Richards and Wilson 2004). Chen et al.'s (2014b) segmentation of Chinese backpackers based on their motivations shows a very similar structure to LokerMurphy's, resulting in three segments - self-actualizers, destination experiencers, and social seekers.

Although previous studies demonstrate that backpackers have multiple motivations, it cannot be said that these motivations play the same role throughout their travel careers. Paris and Teye 
(2010) found that most motivations are fluid concerning backpackers' travel experiences, with cultural knowledge and relaxation being the only two core motivations which are constant during their travel careers. Moreover, in Larsen et al.'s (2011) research, compared with mainstream tourists, backpackers only showed significant differences on the relaxation and luxury motives among six motivational categories. Thus it can be inferred that, among various motivations, some are more important for backpackers. Then it is necessary to identify which motivations are more decisive to make a traveler a backpacker.

\section{Alienation}

Another important aspect of backpacker identity is that of "alienation." The concept of alienation has been discussed in social sciences for many years and the individual's sense of alienation is believed to be closely linked to modernity (Giddens 1991). As modernization accompanies the disenchantment of the traditional world, the individual may feel the loss of security that was guaranteed by previous knowledge, faith, and norms (Beck 1992). During radical transitions of society, especially with the process of urbanization and labor specialization, the individual's experience becomes fragmented and the coherence of his or her self-identity is then threatened. Consequently, a sense of alienation emerges. Based on empirical studies, alienation is found to contain several alternative meanings, such as powerlessness, meaninglessness, normlessness, and isolation (Seeman 1959). Alienation is also derived from different contexts (Maddi, Kobasa, and Hoover 1979): alienation from society or culture (Bernhard, Gebauer, and Maio 2006; Kohn and Schooler 1983), which means one’s estrangement from social surroundings, including social institutions, family and other people; alienation from work (Kanungo 1982; Nair and Vohra 2010), which implies that people gain little intrinsic satisfaction from the work they are doing; and alienation from self (Costas and 
Fleming 2009; Otto and Featherman 1975), which refers to a negative evaluation of self-worth and the detachment from self.

The alienation concept was introduced into tourism research in the 1970s. The sense of alienation, according to Cohen (1979), can be interpreted as a sense of detachment from the home "center", and this was particularly associated in Cohen's work with backpacking culture. He argues that every society possesses a spiritual "center", which is symbolized as the source of ultimate meanings for individuals living in that society. Whilst the individual generally tends to adhere to that center, the processes of modernity are said to push people to strive to escape from inauthentic experiences in their daily lives. Tourism is adopted as a way for individuals to resist the sense of alienation from modern society (MacCannell 1976). Furthermore, Cohen argues that different degrees of alienation from home society can lead to different forms of travel. "Drifting", or the early form of backpacking, was believed to be "both a symptom and an expression of broader alienative forces" among youth (E. Cohen 1973, 94). Stemming from Cohen's work, the sense of alienation has been considered an important characteristic of backpackers.

However, with the change in social-political environments in Western societies, contemporary backpackers are believed to be less alienated from their home center than before. In Uriely et al.'s (2002) research, no more than half of the interviewees are identified as experimental and experiential backpackers, who express alienation from their own culture and routine lives. Sørensen (2003) even describes these contemporary backpackers as "(future) pillars of society”. Indeed, it is argued by Sørensen that they are merely on a temporary suspension from "normal life" and that they have clear intentions to return after their travel. 
It is inevitable that levels and experiences of alienation will vary according to different cultures or societies. Indeed, Maoz (2007) argues that, compared with the broader spectrum of "Western" backpackers, Israeli backpackers are hardly detached from their society; on the contrary, they are strongly tied to Israeli society. Maoz contends that this can be explained by the collective tradition of Israeli culture. China, with a highly collective orientation, has witnessed the most radical social transition in its history in the last four decades. The rapid processes of modernization and urbanization are weakening the traditional lifestyles and values of Chinese people, making alienation a pervasive problem in contemporary China (Sun and Ni 2011). Under this condition, it is pertinent to investigate contemporary Chinese backpackers' sense of alienation.

\section{A brief summary}

As discussed above, for many independent travelers, "backpacker" is not only a social category, but also a label representing their social identities. In relation to the supposed identity factors attributed to largely Western backpackers during the development of this research field, it is pertinent to consider their applicability in the context of Chinese backpackers. In other words, what do Chinese "backpackers" themselves think of the importance of such form- and typerelated factors when they construct their social identities as backpackers? Moreover, what are the distinctive criteria with which Chinese backpackers form and define their "backpacker" identity? This study attempts to address these questions. 


\section{Study Methods}

\section{Sample and procedure}

This study is part of a larger research program focused on Chinese backpackers. The fieldwork was carried out between July 2012 and September 2014 in Sichuan and Yunnan Provinces, two top destinations among Chinese backpackers according to Zhu's (2009) research. The main targeted locations were Chengdu and Daocheng in Sichuan Province, and Dali and Lugu Lake in Yunnan Province. They include four different types of destinations - city, mountain area, historical town, and lake area. They also represent four different ethnic communities, which are Han, Tibetan, Bai, and Mosuo. After long-term ethnographic fieldwork, a self-completed on-site questionnaire survey was applied. A pilot test was conducted with 100 backpackers in August 2013 and the questionnaire was revised based on the results of the pilot test. The formal questionnaire, taking 15-20 minutes to complete, was circulated during July and August 2014, when the destinations are in peak tourist season. As most of the previous studies on backpackers' identity issue apply qualitative research to small samples of respondents, this study hopes to make more representative conclusions using quantitative research and a substantial sample.

As discussed above, the group boundaries of backpackers are highly ambiguous, and this results in difficulties for researchers in identifying their research participants. There are usually two strategies which can be used to find potential respondents. The first is to confirm with respondents whether they consider themselves as backpackers before they are invited to participate in the research. However, this strategy did not fit the current study in that, given the purposes of this research, those who were considered to be backpackers by others but themselves deny this identity needed to be included in the sample. The second strategy is to develop an 
operationalized definition of backpackers. For example, Pearce and Forster (2007) define backpackers as travelers who travel for at least four weeks and live in budget accommodation. However, the trip length of half of Chinese backpackers is less than two weeks (Zhu 2009). Based on her survey, Zhu (2009) argues that the only common and recognizable characteristic of Chinese backpackers is that they carry a backpack as their main travel luggage. Therefore, according to previous research and to the particular concerns of the present research, the potential participants were operationalized as independent travelers, who carry backpacks, and who stay in backpacker hostels during their trips. Respondents were mainly recruited at youth hostels and convenience sampling was used.

Responses from a sample of 350 Chinese backpackers were collected. Excluding 33 unfinished questionnaires, 317 usable questionnaires form the basis for the research (Table 1). The proportion who were male was $55.9 \%$, compared with $44.1 \%$ who were female. Most respondents were young and highly educated. The monthly income of more than half of the respondents was less than 3,000 RMB. These demographic characteristics correspond to previous research on the demographic factors of Chinese backpackers (Zhu 2009).

(Insert Table 1 about here)

\section{Questionnaire and measures}

The questionnaire was developed from previous literature and the researchers' qualitative fieldwork. It consisted of four sections: social identity as a backpacker, travel characteristics, social psychology, and demography and other open questions. All the scales were in a sevenpoint format ranging from "strongly disagree" (1) to "strongly agree" (7). 
The first section dealt with the dependent variable of the research - the respondent's social identity as a backpacker. Two different measurements were applied at the same time to verify each other. The first measurement was operationalized using a single question: "Do you think you are a backpacker?" with a dichotomous response option of Yes/No. The second measurement was a six-item scale developed by Mael and Ashforth (1992), which is one of the most widely used social identity scales (see Appendix).

The second section explored respondents' travel characteristics, including travel behavior and motivations. Five items regarding respondents' travel behavior were developed from LokerMurphy and Pearce' (1995) definition of backpackers. The motivation scale with 14 items was based on Loker-Murphy's (1997) and Paris and Teye's (2010) research on backpackers' motivations.

The third section was on respondents' sense of alienation. Although many scholars emphasize the role of sense of alienation in backpackers' identity construction (E. Cohen 1979; S. A. Cohen 2011; Riley 1988), there is still no systematic and quantitative study addressing this issue. As travel is believed to be a way to escape from the context of daily life, three scales regarding respondents' alienation from different daily contexts were applied: culture estrangement, work alienation, and self-alienation. The scale of culture estrangement with four items was adapted from Kohn and Schooler's (1983) research. The five items of work alienation and three items of self-alienation were extracted from Maddi et al.'s (1979) Scale of Alienation Test. While these three variables tested the general sense of alienation from daily contexts, another scale of detachment from home center emphasized the role of travel in resisting alienation, exploring the relationship between travel and everyday life. Three items were developed based both on 
Cohen's (1979) research on tourist experiences, and on the findings from in-depth interviews conducted prior to the undertaking of the questionnaire survey during the present research.

The last section collected information on respondents' demography. Additional open-ended questions were asked for the purposes of a related research project. The Appendix provides detailed item statements for each variable. All the scales were translated into Chinese. The backtranslation method was applied by three bilingual translators to maintain equivalence between the translated and the original scales and ensure instrument validation.

\section{Data analysis}

All statistical analyses were conducted by using SPSS 20. The analysis was carried out in four steps. First, as a summarization and data reduction technique, exploratory factor analysis (EFA) was applied on dependent and independent variables respectively to identify the underlying structure of the measured variables. Second, according to the question "Do you think you are a backpacker?", the respondents were divided into two groups - "Yes-group" and "No-group". Then t-tests were used to compare these two groups in factors identified in the first step. This could provide preliminary information about the differences between backpackers and other travelers. Third, regression analysis was performed to reveal more detailed information on the relationships between social identity as a backpacker and its indicating factors. As this research applied two different measurements to identify backpackers' identity, logistic regression and multiple linear regression were employed respectively to build different regression models for these two measurements. Finally, comparing the results through three different techniques (t-test and two regression methods) provided a mutually verified understanding of factors influencing the social identities of Chinese backpackers. 


\section{Results}

\section{Exploratory factor analysis}

Prior to the analyses of the relationship between social identity as a backpacker and its indicating factors, exploratory factor analysis was conducted to identify underlying dimensions among these measured variables. For the dependent variable, the scores from six items in the social identity scale were factor analyzed using principal component analysis. The KaiserMeyer-Olkin (KMO) test statistic was 0.898 , and the Bartlett's Test of Sphericity was significant at the 0.00 level, which indicated that the use of factor analysis was appropriate. One factor derived from the EFA was accepted based on an eigenvalue greater than or equal to 1 (in this case, the eigenvalue of this factor was 3.96). Factor loadings of all the items were above 0.6 (Table 2). This factor explained $66 \%$ of the total variance. The result indicated that the items shared one unique construct - social identity as a backpacker. The Cronbach's Alpha was 0.895, which represented a very high reliability of the scale.

For the independent variables, factor analysis could not only reduce the data into fewer dimensions, but also helped resolve the problem of multicollinearity in later regression analyses. Principal component analysis with a Varimax rotation was used to establish factors from 34 items. The KMO result was 0.844 and the Bartlett's Test of Sphericity was 4749.295, with a 0.00 significance level. Eight factors for which the eigenvalues were greater than 1 were identified. One item from the factor "work alienation" ("You find it hard to believe people who actually feel that the work they perform is of value to society") was deleted because its factor loading was below 0.5 (Hair 2009, 115). After deleting that item, factor analysis was re-conducted and the same eight factors with the same loaded items were confirmed, which showed that the structure 
of the variables was very stable. Factors were named based on underlying common traits of variables which loaded on them. The eight factors collectively explained $66.7 \%$ of the total variance. The Cronbach's Alpha of each factor ranged from 0.715 to 0.884 (Table 3 ).

\section{Analysis of differences - $t$-tests}

The question "Do you think you are a backpacker?" was devised to explore respondents' selfjudgement of their identities as backpackers. Although most of these respondents might be recognized as backpackers by others, this question can help us understand whether these respondents were subjectively willing to label themselves as backpackers. According to the answer, respondents were divided into two groups, then independent sample t-test analyses were applied to test differences between these two groups. Excluding seven respondents who did not answer this question, 105 respondents identified themselves as backpackers, while 205 respondents denied their identities as backpackers. This corresponded with the findings from the Western context (O’Reilly 2005; Richards and Wilson 2004), which indicated the identity crisis of "backpackers" with its institutionalization.

As the study employed two different ways to measure respondents' social identities as backpackers, the t-tests helped verify whether these two measurements represented similar constructs. As was expected, the results indicated that every item in the social identity scale showed significant differences between the two groups, and the social identities of Yes-group members were stronger than No-group members (Table 2). So it can be inferred that these two measurements can validly represent respondents' social identities as backpackers in different ways.

(Insert Table 2 about here) 
In Table 3, 4 and 5, the differences between the two groups with reference to eight factors which might indicate Chinese backpackers' social identities are shown. Concerning travel behavior, it was surprising that no differences were found between these two groups (Table 3). The results indicated that respondents who denied their identities as backpackers also traveled in a backpacker-like manner. Moreover, the two groups held similar opinions about these norms. Both of them considered that to organize their journey independently was the most important norm for them $(M=6.05)$, while they regarded the length of travel as the least important one (M $=4.58)$.

(Insert Table 3 about here)

As can be seen in Table 4, the factor analysis identified three dimensions of respondents' travel motives - leisure, external-oriented exploration, and self-achievement. Overall, the rank order of these three motives was slightly different between groups. Both of them ranked the external-oriented exploration motive as the most important one among the three factors. But the Yes-group members considered the self-achievement motive as the second most important motive, while No-group members ranked the leisure motive higher than the self-achievement motive. However, the t-test results indicated that the statistical differences between the two groups were only found for the external-oriented exploration motive. Yes-group members were more driven by this motive, especially the need to experience thrills and adventure, to strengthen their will and resolve, and to experience different cultures. Although the two groups had similar 
strengths for the self-achievement motive, the Yes-group members were more desirous of being recognized by other people through backpacking activities.

(Insert Table 4 about here)

Regarding respondents' sense of alienation, this research investigated four related variables (Table 5). Culture estrangement, work alienation and self-alienation represented respondents' general social psychology in their everyday lives. Among these three variables, respondents showed the highest sense of alienation from their cultural environments, and lowest sense of alienation from their work. According to the t-test results, no differences were observed in selfalienation, but the Yes-group showed significantly higher cultural estrangement and work alienation than the No-group. To be specific, the Yes-group felt more alienated from the culture of the social class and the nation they belonged to. They also held more negative attitudes to their work, such as they believed that their work was meaningless and boring, and they did not enjoy it at all.

The variable "detachment from home center" indicated whether these respondents treated tourism as a way to resist their sense of alienation. The results of the t-tests showed that the Yesgroup had significantly higher detachment from home center than the No-group. Of three statements in the scale, both groups had a strong willingness to seek a sense of belonging to destinations they had previously visited. But the Yes-group members showed more interest in adopting alternative lifestyles from "other" centers.

(Insert Table 5 about here) 


\section{Binary logistic regression modeling}

After the t-test results provided preliminary information about the differences between the two groups concerning the eight factors, regression analyses were applied to build further understanding about how these factors indicated respondents' social identities as backpackers. As the first measurement of the dependent variable was binary ("Do you think you are a backpacker?"), binary logistic regression with backward stepwise (conditional) selection procedure was conducted. The eight factors were entered into the model to determine if they were significant predictors. The removal of variables is according to the probability of the likelihood-ratio statistic based on conditional parameter estimates. After four steps, three variables (self-achievement motive, culture estrangement, and travel behavior) were removed and the final model was established (Table 6). The model fit the data well, with the HosmerLemeshow statistic of $\chi^{2}=10.132(p=0.256>0.10)$.

The external-oriented exploration and leisure motives remained in the model, but they indicated respondents' social identities in contrary ways. The external-oriented exploration motive, yielding the highest regression coefficient value $(B=0.486)$, was the most important motive for backpackers, and it seems to have helped strengthen their self-identity as backpackers. However, a negative relationship was observed between the leisure motive and self-judgement as a backpacker. This means that those with stronger leisure motives were less likely to self-identify as backpackers.

In terms of alienation, only culture estrangement was excluded from the final model. The positive regression coefficient of work alienation $(\mathrm{B}=0.328)$ indicated that those who had 
higher work alienation tended to label themselves as backpackers, while those who could gain meaning from their work were less likely to treat backpacking as their spiritual sustenance. On the contrary, it was interesting to note that self-alienation had a negative relationship with backpackers' social identities $(\mathrm{B}=-0.314)$, which may imply that Chinese backpackers are not self-alienated individuals. Detachment from the home center, with the second highest regression coefficient $(\mathrm{B}=0.401)$, was a good predictor of self-identification as a backpacker.

(Insert Table 6 about here)

\section{Multiple linear regression modeling}

The second measurement of the dependent variable was a continuous variable (social identity scale), so multiple linear regression with the stepwise selection procedure was carried out. The eight factors were entered into the model and two (self-alienation and leisure motive) were excluded from the final model (Table 7). The final model was accepted with its $\mathrm{R}^{2}$ of 0.233 , and F value of $13.444(\mathrm{p}<0.001)$.

As can be seen in Table 7, all the remaining factors had positive relationships with respondents' social identities as backpackers. To escape from home center and seek new centers was confirmed to be an important factor related to their identities, with the highest regression coefficient among the eight factors $(\mathrm{B}=0.294)$. Concerning motivations, besides the externaloriented exploration motive, the self-achievement motive was also identified as a good indicator for respondents' sense of belonging to the backpacker group. Travel behavior, considered as the visible boundary of backpackers, for its first time in this analysis, was found to be a predictor for 
Chinese backpackers' identity construction ( $\mathrm{B}=0.158)$. Finally, the Chinese backpackers again showed their strong connection to the sense of alienation, especially work alienation $(\mathrm{B}=0.155)$ and cultural estrangement $(B=0.147)$.

(Insert Table 7 about here)

\section{Discussion and Conclusions}

Deriving results from three different methods, this research provides a comprehensive understanding of key factors influencing Chinese backpackers' social identities. As can be seen in Figure 1, of the eight factors, the external-oriented exploration motive, work alienation and detachment from home center, emerging as significant factors in all the three methods, are the most reliable indicators of Chinese backpackers' social identities. Additionally, the cultural estrangement factor was significant in the t-tests and multiple linear regression. The relationships between four other factors - travel behavior, leisure motive, self-achievement motive, and selfalienation - and Chinese backpackers' social identities were less evident.

(Insert Figure 1 about here)

Whilst, after Loker-Murphy and Pearce (1995), travel behavior and form-related attributes are widely accepted as the criteria to identify whether a traveler was a backpacker (Chen, Bao, and Huang 2014a; Pearce and Foster 2007; Uriely, Yonay, and Simchai 2002), this study has shown that travel behavior cannot identify Chinese backpackers very effectively. Although formrelated criteria can indeed successfully differentiate backpackers from traditional mass tourists, 
with the continuous institutionalization of contemporary backpackers, it is becoming increasingly difficult to distinguish "backpackers" from other independent tourists merely according to their travel behavior. Indeed, among the five behavioral norms, budget and length of trip are not homogeneous among Chinese backpackers. Moreover, because of the gradual "massification" of backpacking in China, it can be reasonably inferred that the relationships between these behavioral characteristics and Chinese backpackers will get weaker, and the visible boundary between backpackers and other independent travelers will become more obscure. Therefore, it can be suggested that travel behavior, or form-related attributes, are not core factors in social identity construction as a "backpacker" among this Chinese tourist group. Instead, some type-related attributes are found to be core "backpacker" identity criteria.

This study has identified three key motives of the Chinese backpacker: leisure, externaloriented exploration, and self-achievement, which represents a similar structure to Chen et al.'s (2014b) research on Chinese backpackers. Of the three motives, the external-oriented exploration motive is the most reliable indicator of Chinese backpackers' identities. Backpackers are found to be more driven by this motive than other independent travelers. The other two motives leisure and self-achievement - are less important for Chinese backpackers, of which the latter is more valued than the former. As highlighted by many scholars, backpacking is a way for individuals to make self-change (Noy 2004), to reconstruct their personal identities (S. A. Cohen 2010), and to achieve their personal development (Chen, Bao, and Huang 2014a; Pearce and Foster 2007). So rather than seeking fun and pleasure, backpackers tend to construct their journeys as a more serious, or even "semi-religious" experiences (Noy 2004). In line with this, the present research finds that a leisure motivation has a negative relationship to Chinese backpacker's social identities. The more an independent traveler is driven by the leisure motive, 
the more he/she tends to deny his/her identity as a backpacker. In sum, it can be concluded that the external-oriented exploration motive is the most "backpacker-oriented" motive for Chinese backpackers. From the perspective of motivations, Chinese backpackers can be characterized as those who are more willing to explore the unknown world and to seek experiences of risk and authenticity.

In relation to the sense of alienation, this study has systematically examined this issue among Chinese backpackers. Since this characteristic of backpackers was first noted by Cohen (1973), with the ongoing evolution of backpackers, the relationship between alienation and backpacker identity has been questioned (Maoz 2007; Uriely, Yonay, and Simchai 2002). Indeed, in his later research, Cohen himself concedes that the contemporary social-cultural circumstances of Western societies "make it implausible to link backpacking with alienation" (E. Cohen 2003, 105). The present study, on the one hand, finds Chinese backpackers also show a relatively low sense of alienation according to their generally low mean scores for the alienation scale items. In this sense, the finding confirms the arguments of previous researchers that the link between backpacking and alienation may be weaker than before. But on the other hand, the comparison between backpackers and other travelers tells another aspect of the story. A sense of alienation is still found to be a significant feature of Chinese backpackers in differentiating them from other tourists. Of three examined senses of alienation, the feeling of work alienation plays an important role in Chinese backpackers' identity construction. This point may be linked to social transformations in China from a planned economy to a market economy over the past three decades (Luo 2011). Today, young people face fiercer competition and more unstable work conditions than their parents' generation. Backpacking, bestowed with the ideal of freedom, thus it becomes a popular way for young people to release the stress they experience in their 
alienation from work. Besides work alienation, the notion of cultural estrangement is also found to be a good predictor for Chinese backpackers' social identity. Many respondents expressed the idea that they feel misunderstood by the people who surround them in their daily life, and thus seek "belonging" within the backpacker group (believing other backpackers share very similar values and views). This point may explain why Chinese backpackers are found to be highly dependent on the virtual backpacker communities (Lim 2008; Luo, Huang, and Brown 2015) and keen to look for travel companions with other backpackers (Miao and Bao 2007).

Interestingly, self-alienation had a weak and negative relation to Chinese backpackers' identity construction. This implies that, different from drifters, contemporary Chinese backpackers are neither nihilistic nor pessimistic. They might feel alienated from the society in which they live, but they still are actively seeking the meaning of life through backpacking. This can also be confirmed by the last factor "detachment from home center", which is one of the most reliable indicators of the identity as a Chinese backpacker. Experiencing alienation from everyday life and work, people in China who become backpackers tend to believe that alternative lifestyles and values may help them resist or reduce the sense of alienation. Therefore, although they may experience a sense of alienation, they still maintain their optimism about life and actively engage (through backpacking in this case) to (re)construct the meaning in their lives.

In sum, this research set out to explore what it is that makes one a "backpacker" in China. The study extends existing knowledge of backpackers in the Chinese context by adopting quantitative techniques to examine the relationships between backpackers' social identity and several form- and type-related attributes which have previously been widely discussed. The findings infer that Chinese backpackers construct their social identity in type-related, more than form-related, ways. With the continuing growth and increasing institutionalization of 
backpacking in China in recent years, the visible boundaries between backpackers and other, more traditional, tourists are becoming increasingly blurred. However, "backpacker" is still used as an expression of identity. To maintain group meaning and values, Chinese backpackers tend to emphasize more type-related attributes. Rather than defining Chinese backpackers by their behavioral characteristics, it is important to regard the term "backpacker" more as a social identity. Indeed, this study has emphasized that it is backpackers themselves who decide what backpackers are, and so it is important that researchers pursue emic approaches in future backpacker research.

This research has practical implications for the tourism sector. Chinese backpackers appear to eschew traditional travel distribution channels and tourism operations. They do not particularly like to singled out as "backpackers" and it is inappropriate to define them only by travel behaviors. Low prices such as in budget accommodations are not always the best strategy to attract Chinese backpackers. YHA China recognizes this and says in its official website, "We are an 'International Youth Hostel', not a budget hotel. We promote cultural exchange, conservation of the environment, love and care of nature, simple but quality living, do-it-yourself and help those who help themselves" (YHA China 2016).

Tourism policy-makers, operators and destination marketing organizations should pay more attention to these Chinese travelers' psychological and emotional demands when conducting planning, development, and marketing. For example, influenced by the feeling of work alienation in daily life, the slogan "shou zou jiu zou", translating into setting out on a journey as soon as one is struck by the idea of traveling and encouraging people to suspend their work to travel, has gained in popularity among contemporary Chinese backpackers. Some tourism operators in China have adopted this slogan in their advertising to attract this market. An emotional echo with 
backpackers like this one, which strengthens their identities and sense of group belonging, will better equip destinations and operators to attract and serve the market.

For tourism practitioners and researchers, the idiom of "you can't judge a book by its cover" seems very apt when considering Chinese backpackers, and perhaps even backpackers in general. Seeing groups of young people toting backpacks in vacation destinations should not be taken as a signal that they are all alike. The challenge for tourism researchers in the future is to delve deeper with qualitative and quantitative inquiries to more clearly and comprehensively reveal the psychological and lifestyle differences among these 'travelers.' Tourism practitioners need to engage online with these youthful sojourners, especially in their favored social media channels, and mine the content that they generate for clues to unlocking what they like, need, and require.

Finally, several limitations of this study need to be considered. First, as discussed above, "backpacker" is more a socially constructed category that can be bestowed with different forms and meanings in different social-historical contexts. Therefore, it would be unwise to generalize these findings to backpackers from other regions. More studies from various social backgrounds are called for to extend the scope of backpacking research. Second, it should also be noted that the goodness-of-fit of the multiple regression model is relatively low, which suggests that the eight examined factors may not provide enough explanation for the dependent variable. In other words, this indicates that there are some other unexplored factors which are related to Chinese backpackers' social identities. These tested factors, while showing significant relationships with backpackers' social identities, do not tell the whole story. This provides opportunity for future research, most likely employing qualitative approaches, to identify these unexplored factors. 


\section{References}

Adler, Judith. 1985. "Youth on the road: Reflections on the history of tramping." Annals of Tourism Research 12 (3):335-54.

Ateljevic, Irena, and Stephen Doorne. 2004. "Theoretical encounters: A review of backpacker literature." In The global nomad: Backpacker travel in theory and practice, edited by G. Richards and J. Wilson, 60-76. Bristol, UK: Channel View Publications.

Beck, Ulrich. 1992. Risk society: Towards a new modernity. London, UK: Sage.

Bernhard, Mark M., Jochen E. Gebauer, and Gregory R. Maio. 2006. "Cultural estrangement: The role of personal and societal value discrepancies." Personality and Social Psychology Bulletin 32 (1):78-92.

Boorstin, Daniel J. 1964. The image: A guide to pseudo-events in America. New York: Harper \& Row.

Chen, Ganghua, Jigang Bao, and Songshan Huang. 2014a. "Developing a scale to measure backpackers' personal development." Journal of Travel Research 53 (4):522-36.

Chen, Ganghua, Jigang Bao, and Songshan Huang. 2014b. "Segmenting Chinese backpackers by travel motivations." International Journal of Tourism Research 16 (4):355-67.

Chen, Hanyu, and Betty Weiler. 2014. "Chinese donkey friends in Tibet - Evidence from the cyberspace community." Journal of China Tourism Research 10 (4):475-92.

Cohen, Erik. 1972. "Toward a sociology of international tourism." Social Research 39 (1):16482.

Cohen, Erik. 1973. "Nomads from affluence: Notes on the phenomenon of drifter-tourism." International Journal of Comparative Sociology 14 (1-2):89-103.

Cohen, Erik. 1979. "A phenomenology of tourist experiences." Sociology 13 (2):179-201. 
Cohen, Erik. 2003. "Backpacking: Diversity and change." Journal of Tourism and Cultural Change 1 (2):95-110.

Cohen, Erik. 2006. "Pai - A backpacking enclave in transition." Tourism Recreation Research $31(3): 11-27$.

Cohen, Scott A. 2010. "Personal identity (de)formation among lifestyle travellers: A doubleedged sword." Leisure Studies 29 (3):289-301.

Cohen, Scott A. 2011. "Lifestyle travellers: Backpacking as a way of life." Annals of Tourism Research 38 (4):1535-55.

Costas, Jana, and Peter Fleming. 2009. "Beyond dis-identification: A discursive approach to selfalienation in contemporary organizations." Human Relations 62 (3):353-78.

Desforges, Luke. 1998. "Checking out the planet: Global representations/local identities and youth travel." In Cool places: Geographies of youth culture, edited by Tracey Skelton and Gill Valentine, 175-92. London, UK: Routledge.

Desforges, Luke. 2000. "Travelling the world: Identity and travel biography." Annals of Tourism Research 27 (4):926-45.

Elsrud, Torun. 2001. "Risk creation in traveling: backpacker adventure narration." Annals of Tourism Research 28 (3):597-617.

Enoch, Yael, and Ronit Grossman. 2010. "Blogs of Israeli and Danish backpackers to India." Annals of Tourism Research 37 (2):520-36.

Giddens, Anthony. 1991. Modernity and self-identity: Self and society in the late modern age. Redwood City, CA: Stanford University Press.

Hair, Joseph F., William C. Black, Barry J. Babin and Rolph E. Anderson. 2010. Multivariate data analysis, 7th ed. New York: Pearson. 
Hannam, Kevin, and Anya Diekmann. 2010. "From backpacking to flashpacking: Developments in backpacker tourism research." In beyond backpacker tourism: Mobilities and experiences, edited by Kevin Hannam and Anya Diekmann, 1-7. Bristol, UK: Channel View Publications.

Have, Paul ten. 1974. "The counter culture on the move. A field study of youth tourists in Amsterdam." Mens en maatschappij 49 (3):297-315.

Hindle, Natalie, Andrew Martin, and Robert Nash. 2015. "Tourism development and the backpacker market in Highland Scotland." Tourism and Hospitality Research 15 (3):17892.

Hogg, M. A., Deborah J. Terry, and Katherine M. White. 1995. "A tale of two theories: A critical comparison of identity theory with social identity theory." Social psychology quarterly:25569.

Howard, Robert W. 2007. "Five backpacker tourist enclaves." International Journal of Tourism Research 9 (2):73-86.

Kanungo, Rabindra N. 1982. Work alienation: An integrative approach. New York: Greenwood Publishing Group.

Kohn, Melvin L., and Carmi Schooler. 1983. Work and personality: An inquiry into the impact of social stratification. New York: Ablex Publishing.

Lamont, Michele, and Marcel Fournier. 1992. Cultivating differences: Symbolic boundaries and the making of inequality. Chicago, IL: The University of Chicago Press.

Larsen, Svein, Torvald Øgaard, and Wibecke Brun. 2011. "Backpackers and mainstreamers: Realities and myths." Annals of Tourism Research 38 (2):690-707. 
Lim, Francis Khek Gee. 2008. "'Donkey friends' in China: The internet, civil society, and the emergence." In Asia on Tour: Exploring the Rise of Asian Tourism, edited by Tim Winter, Peggy Teo and Tou Chuang Chang, 291-301. London, UK: Routledge.

Loker-Murphy, Laurie. 1997. "Backpackers in Australia: A motivation-based segmentation study." Journal of Travel \& Tourism Marketing 5 (4):23-45.

Loker-Murphy, Laurie, and Philip L. Pearce. 1995. "Young budget travelers: Backpackers in Australia." Annals of Tourism Research 22 (4):819-43.

Luo, Xianrong, Songshan Huang, and Graham Brown. 2015. "Backpacking in China: A Netnographic analysis of donkey friends' travel behaviour." Journal of China Tourism Research 11 (1):67-84.

Luo, Zhenglin. 2011. "The Changing Tendency of Chinese Social Psychology in Evolution Era." Lanzhou Academic Journal, (10):33-39.

MacCannell, Dean. 1976. The tourist: A new theory of the leisure class. New York: Schocken.

Maddi, Salvatore R., Suzanne C. Kobasa, and Marlin Hoover. 1979. "An alienation test." Journal of Humanistic Psychology 19 (4):73-76.

Mael, Fred, and Blake E. Ashforth. 1992. "Alumni and their alma mater: A partial test of the reformulated model of organizational identification." Journal of organizational Behavior 13 (2):103-23.

Maoz, Darya. 2007. "Backpackers' motivations: The role of culture and nationality." Annals of Tourism Research 34 (1):122-40.

Miao, Xueling, and Jigang Bao. 2007. "Grounded theory of non-standardized groups travel." Tourism Tribune 22 (8):48-54. 
Mukerji, Chandra. 1978. "Bullshitting: Road Lore among Hitchhikers." Social Problems 25 (3):241-52.

Munt, Ian. 1994. "The other' postmodern tourism: Culture, travel and the new middle classes." Theory, Culture and Society 11 (3):101-23.

Nair, Nisha, and Neharika Vohra. 2010. "An exploration of factors predicting work alienation of knowledge workers." Management Decision 48 (4):600-15.

Noy, Chaim. 2004. "This trip really changed me: Backpackers' narratives of self-change." Annals of Tourism Research 31 (1):78-102.

O'Regan, Michael. 2016. "A backpacker habitus: the body and dress, embodiment and the self." Annals of Leisure Research:1-18.

O’Reilly, Camille Caprioglio. 2005. "Tourist or traveller? Narrating backpacker identity." In Discourse, communication and tourism, edited by Adam Jaworski and Annette Pritchard 150-69. Bristol, UK: Channel View Publications.

O’Reilly, Camille Caprioglio. 2006. "From drifter to gap year tourist: Mainstreaming backpacker travel." Annals of Tourism Research 33 (4):998-1017.

Otto, Luther B, and David L Featherman. 1975. "Social structural and psychological antecedents of self-estrangement and powerlessness." American Sociological Review:701-19.

Ong, Chin-ee, and Hilary du Cros. 2012. "The post-Mao gazes: Chinese backpackers in Macau." Annals of Tourism Research 39 (2):735-54.

Paris, Cody Morris. 2012. "Flashpackers: An emerging sub-culture?" Annals of Tourism Research 39 (2):1094-115.

Paris, Cody Morris, and Victor Teye. 2010. "Backpacker motivations: A travel career approach." Journal of Hospitality Marketing \& Management 19 (3):244-59. 
Pearce, Philip L. 1990. The backpacker phenomenon - preliminary answers to basic questions. Department of Tourism, Jams Cook University of North Queensland.

Pearce, Philip L., and Faith Foster. 2007. "A “university of travel”: Backpacker learning." Tourism Management 28 (5):1285-98.

Richards, Greg, and Julie Wilson. 2004. "The global nomad: Motivations and behavior of independent travellers worldwide." In The global nomad: Backpacker travel in theory and practice, edited by G. Richards and J. Wilson, 14-39. Bristol, UK: Channel View Publications.

Riley, Pamela J. 1988. "Road culture of international long-term budget travelers." Annals of Tourism Research 15:313-28.

Seeman, Melvin. 1959. "On the meaning of alienation." American Sociological Review:783-91. Sørensen, Anders. 2003. "Backpacker ethnography." Annals of Tourism Research 30 (4):847-67. Sun, Qi'ang, and Qiusi Ni. 2012. "Alienation in the spiritual life of contemporary youths under the context of modernity." China Youth Study (7):10-14.

Tajfel, Henri. 1982. Social identity and intergroup relations. New York: Cambridge University Press.

Tajfel, Henri, and John C. Turner. 1979. "An integrative theory of intergroup conflict." The social psychology of intergroup relations 33 (47): 74.

Tomazos, Konstantinos. 2016. "Backpacking Through an Ontology of Becoming: A Neverending Cycle of Journeys." International Journal of Tourism Research 18 (2):140-148.

Uriely, Natan, Yuval Yonay, and Dalit Simchai. 2002. "Backpacking experiences: A type and form analysis." Annals of Tourism Research 29 (2):520-38. 
Vogt, Jay W. 1976. "Wandering: Youth and travel behavior." Annals of Tourism Research 4 (1):25-41.

Welk, Peter. 2004. "The beaten track anti-tourism as an element of backpacker identity." In The global nomad: Backpacker travel in theory and practice, edited by G. Richards and J. Wilson, 77-90. Bristol, UK: Channel View Publications.

Wilson, Julie, and Greg Richards. 2008. "Suspending reality: An exploration of enclaves and the backpacker experience." Current Issues in Tourism 11 (2):187-202.

YHA China. 2016. "We are not a budget hotel." http://www.yhachina.com/index.php?hostID=1 (accessed December 30, 2016)

Zhu, Xuan. 2009. Theoretical and empirical study on backpacker tourism. Beijing, China: China Tourism \& Travel Press. 